\title{
Shear Band Formation in a Shaped Rheocast Aluminium Component at Various
}

\author{
Plunger Velocities \\ M. BLADH ${ }^{1}$, M. WESSÉN ${ }^{2}$ and A. K. DAHLE ${ }^{3}$ \\ 1 Swerea SWECAST AB, Box 2033, 55002 Jönköping, Sweden \\ 2 Materials and Manufacturing- Casting, School of Engineering, Jönköping University, 55111 Jönköping, Sweden \\ 3 Materials Engineering, The University of Queensland, Brisbane Queensland 4072, Australia
}

\begin{abstract}
Significant progress has been made in recent years in understanding and modelling the rheology of semi-solid metals. These models show the effects of the microstructure in terms of size and morphology of globules on the material response. More recently it has been shown that semi-solid metals can behave as compacted granular materials such as sand. A particular signature of such deformation is that the deformation becomes concentrated into shear bands which are 10-20 grains wide. Such bands have also been observed in a range of cast products. Recently, it has been clearly shown that shear bands in HPDC products are also the results of Reynolds dilatancy. Shear bands are also known to be a common feature in semi-solid metal products. This paper investigates the segregation banding in SSM material and its dependence of plunger velocity. Shaped castings were made with the RHEOMETALTM process with a range of different plunger velocities. The microstructural characteristics have been investigated, with a particular emphasis on shear bands. It is shown that ingate velocities influence the location and characteristics of the shear bands.
\end{abstract}

Keywords: Rheocasting, Shear bands, Segregation, Al-alloys, RHEOMETAL ${ }^{\mathrm{TM}}$

\section{Introduction}

High pressure die casting (HPDC) is one of the major processes used to make cast products for the automotive industry. Furthermore, when used to make semi-solid metal (SSM) castings the HPDC process has several advantages compared to conventional casting processes such as reduced porosity and improved mechanical properties. In ordinary HPDC products it is common to observe positive macrosegregation of solute concentrated in what is known as defect bands. These bands follow the contour of the casting surface, usually of near-eutectic composition and may also contain porosity and/or cracks.

Gourlay et al. [1]-[3] have studied the formation of these defect bands and found that they contain a larger fraction Al-Si eutectic than the surroundings. Further studies by Laukli et al. [4]-[5] and Gourlay et al. [6]-[7], and later Otarawanna et al. [8]-[12] show that partially solidified eqiaxed alloys can exhibit the characteristics of a cohesionless compacted granular material, such as volumetric response to shear, known as Reynolds' dilatancy. Furthermore, research in the area of granular materials [10] points to a specific relationship between band thickness and grain size, i.e. the bands are 10-20 grains wide. This relationship is seen in controlled rheology experiments on partially solidified alloys as well.

Still today, there are different opinions on how these defect bands form during solidification in HPDC process. Cao et al. [13] proposes two different mechanisms for the formation of defect bands, where one is dependent on the presence of externally solidified crystals, ESC. Gourlay et al. [1] on the other hand show that ESC has no direct involvement in the mechanism of band formation, but the presence of ESC may indirectly influence its formation. The SSM HPDC processes are different than regular HPDC process in that piston velocities are much slower, due to the high viscosity of the slurry. Also, the slurry consists of globular pre-solidified crystals, instead of equiaxed dendrites. This would be expected to have an effect on the formation of the defect bands, and also to a shift of the coherency point of the alloy. To obtain a more sound material and to increase the mechanical properties of the component, it is therefore important to investigate these bands further. 
In the present study, HPDC process parameters are coupled with microstructure and investigated with respect to defect banding. The process parameter changed is the piston velocity during the second phase.

The characteristics of the microstructure are then investigated and discussed with respect to band thickness and location in the component.

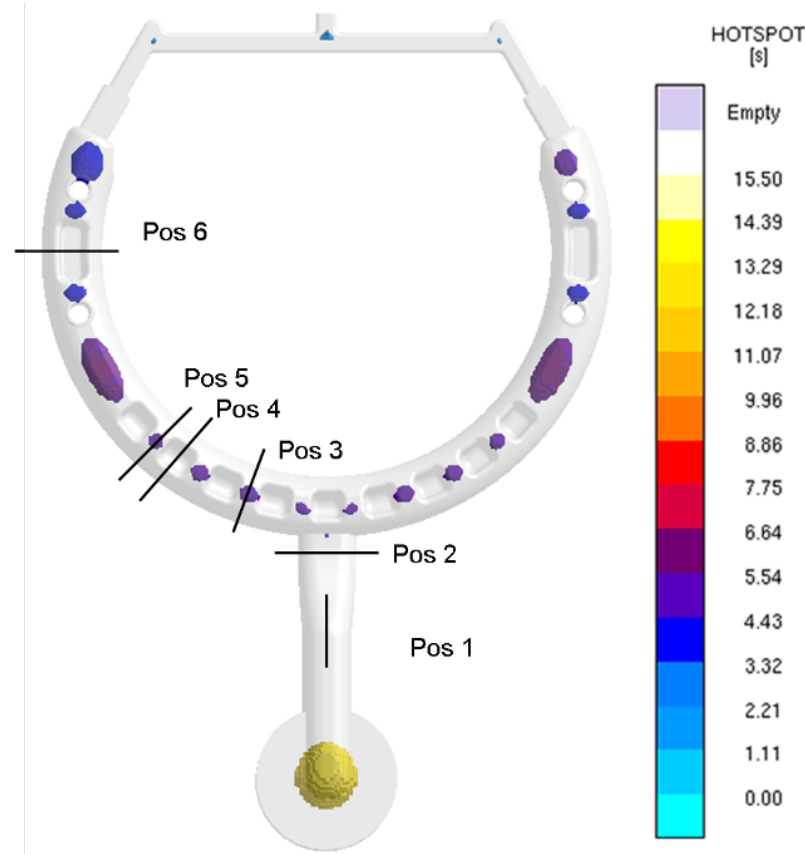

Fig.1 The component marked with the positions, 1-6, examined for microstructure analyses. Also showing is the hot spot regions from simulation

\section{Experimental}

In this study, a commercial component manufactured by the RHEOMETAL ${ }^{\mathrm{TM}}$ process was used to investigate the appearance of defect bands in the microstructure of a high-pressure die cast component. For the slurry preparation, a commercial RHEOMETAL ${ }^{\text {TM }}$ station was used in combination with a Frech 700-tonne cold chamber die casting machine for casting the component. Further information about the RHEOMETAL ${ }^{\mathrm{TM}}$ process can be found elsewhere [13]. The slurry was prepared to a fraction solid of approximately $30 \%$. The shot sleeve diameter was $80 \mathrm{~mm}$ and its length was $480 \mathrm{~mm}$ and the fill fraction was $25 \%$.

The samples were sectioned at fixed positions, see figure 1, and prepared using standard metallographic techniques. A total of 7 samples were investigated at 3 positions each. Position 1 was examined parallel to the slurry bulk flow direction. Positions 2 and 3 were examined perpendicular to the slurry bulk flow direction. The casting from trial 3 was investigated in greater detail and the study was extended to six positions. All of them were sectioned perpendicular to the bulk flow. An optical microscope, LOM (Leica MEF4A and Leica M205C), was used to characterise the microstructure and to examine the influence of different piston velocities. To enhance the microstructure, the samples were etched in modified Murakami etchant, $(60 \mathrm{ml} \mathrm{H} 2 \mathrm{O}+10 \mathrm{~g} \mathrm{NaOH}+$ $5 \mathrm{~g} \mathrm{~K} 3 \mathrm{Fe}(\mathrm{CN}) 6)$. Scanning electron microscopy, SEM (Hitachi VP-SEM, S-3700N) was used in combination with energy-dispersive X-ray spectroscopy, EDX, to perform composition mapping.

Table 1 Chemical composition in wt $\%$ of the alloy

\begin{tabular}{ccccccccc}
\hline Alloy & $\mathrm{Si}$ & $\mathrm{Fe}$ & $\mathrm{Cu}$ & $\mathrm{Mn}$ & $\mathrm{Mg}$ & $\mathrm{Zn}$ & $\mathrm{Ti}$ & $\mathrm{Sr}$ \\
\hline Rheo1 & 5.69 & 0.50 & 2.26 & 0.27 & 0.02 & 0.56 & 0.02 & 0.0003 \\
\hline
\end{tabular}

The piston velocity varied from $0.05 \mathrm{~m} / \mathrm{s}$ to $0.9 \mathrm{~m} / \mathrm{s}$ (same for 1 st and 2 nd phase). Table 2 shows parameters associated with the test run. To ensure a steady-state operating environment, at least twenty samples were cast for each piston velocity.

Table 2 Shot parameters for the trials

\begin{tabular}{cccccccc}
\hline Trial & 1 & 2 & 3 & 4 & 5 & 6 & 7 \\
\hline $\begin{array}{c}\text { Piston velocity } \\
{[\mathrm{m} / \mathrm{s}]}\end{array}$ & 0.05 & 0.10 & 0.15 & 0.25 & 0.40 & 0.60 & 0.90 \\
\hline $\begin{array}{c}\text { Slurry temp } \\
{\left[{ }^{\circ} \mathrm{C}\right]}\end{array}$ & 604 & 604 & 604 & 606 & 605 & 607 & 607 \\
\hline $\begin{array}{c}\text { Die preheat } \\
\text { temp }\left[{ }^{\circ} \mathrm{C}\right]\end{array}$ & 160 & 140 & 140 & 140 & 140 & 140 & 140 \\
\hline $\begin{array}{c}\text { Furnace temp } \\
{\left[{ }^{\circ} \mathrm{C}\right]}\end{array}$ & 679 & 679 & 678 & 684 & 681 & 679 & 682 \\
\hline
\end{tabular}

\section{Results and discussion}

Fig. 2 shows typical images from three different piston velocities. Images marked with a yellow arrow, symbolises the bulk flow direction. The lighter areas represent the eutectic phase, $\mathrm{Al}-12 \mathrm{w} \% \mathrm{Si}$, and the darker areas in the samples show the primary phase, Al. The white spots are small pores, mainly located in the hot spot area. None of the pores appear to be concentrated within the band, which is usually the case for HPDC and $\mathrm{Mg}$-alloys, as reported in previous research [10].

It can be seen that that the piston velocity has an influence on the location and number of segregation bands in the component. Previous work [10] [11] on SSM and HPDC has shown banding in thixomoulded material. This implies that strain localisation occur even in SSM casting. It was found that the bands were much narrower than ten primary globules thick, suggesting a different mechanism for band formation. 


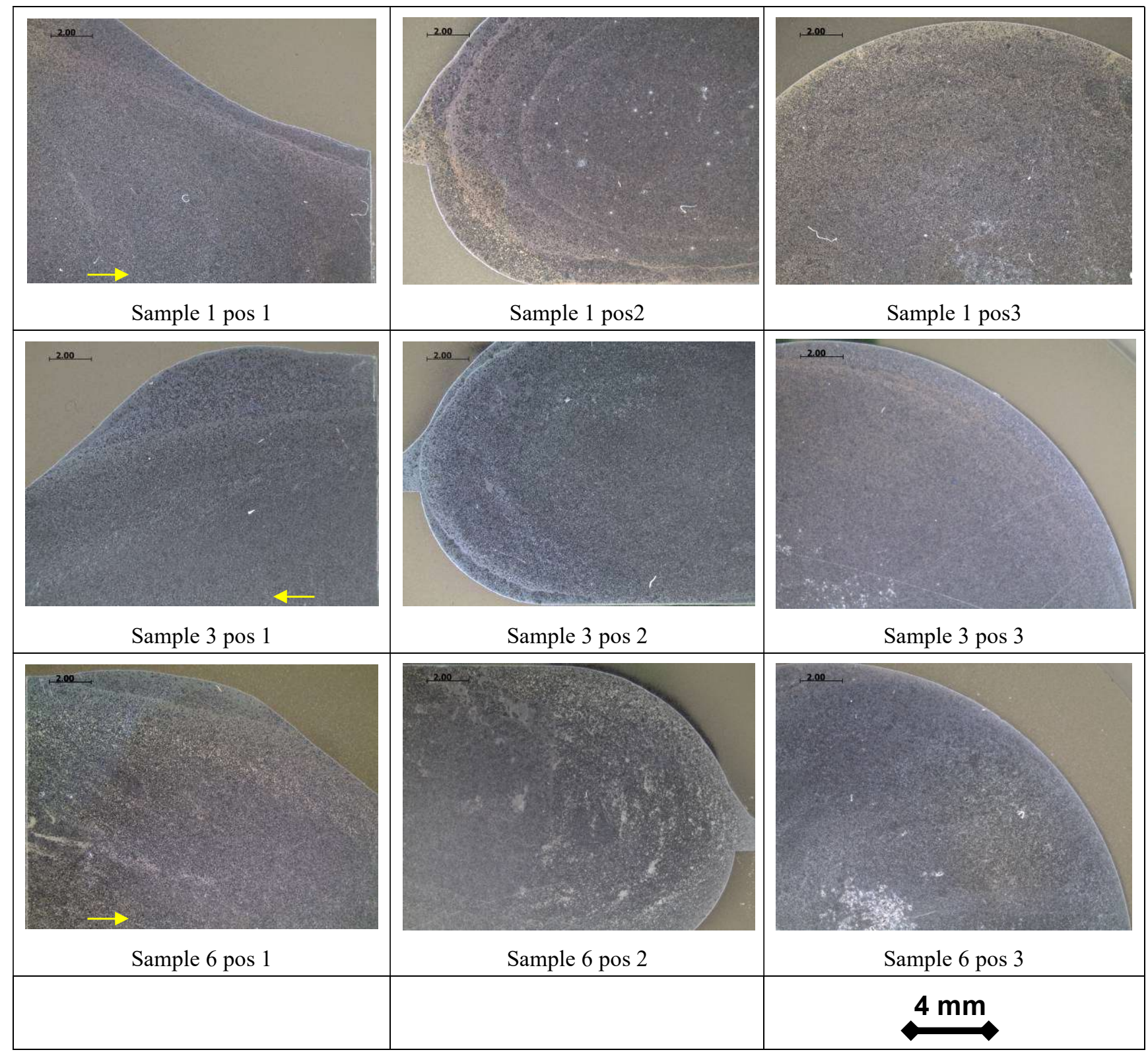

Fig.2 Typical etched optical images for three different piston velocities; starting with $0.05,0.15$ and $0.60 \mathrm{~m} / \mathrm{s}$ from row 1 through 3 respectively. Positions from where the sample is taken in the shaped component can be seen in figure 1 . Arrow in the images $\rightarrow$ shows the bulk flow direction. Images left unmarked have bulk flow perpendicular to the polished surface; into the page.

An earlier study [14] using the RHEOMETAL process has shown that a phase 1 velocity of $0.15 \mathrm{~m} / \mathrm{s}$ gave the best filling and least amount of pores. To get a broader view three more sections, positions $4-6$, were polished and examined in this study, as shown in Fig. 3. It is evident that shear banding is present in all sections. Positions 4 and 6 have $\sim 30 \%$ decrease in cross section area, which result in an increase in bulk flow velocity. However, there is no clear difference in neither position nor width of the bands in comparison with positions 3 and 5 in Fig. 3. As a result, in this study it appears that the internal flow velocity changes has little influence on the band position. However, different piston velocities seem to have an effect on the band positions as previously shown in fig 2 . In this study the very slow piston velocities used in trial 1 could have an impact on the HPDC machine's ability to function normally. At these very low velocities the machine was operating unevenly, and could therefore be the origin of the multi layered band observed in fig. 2 


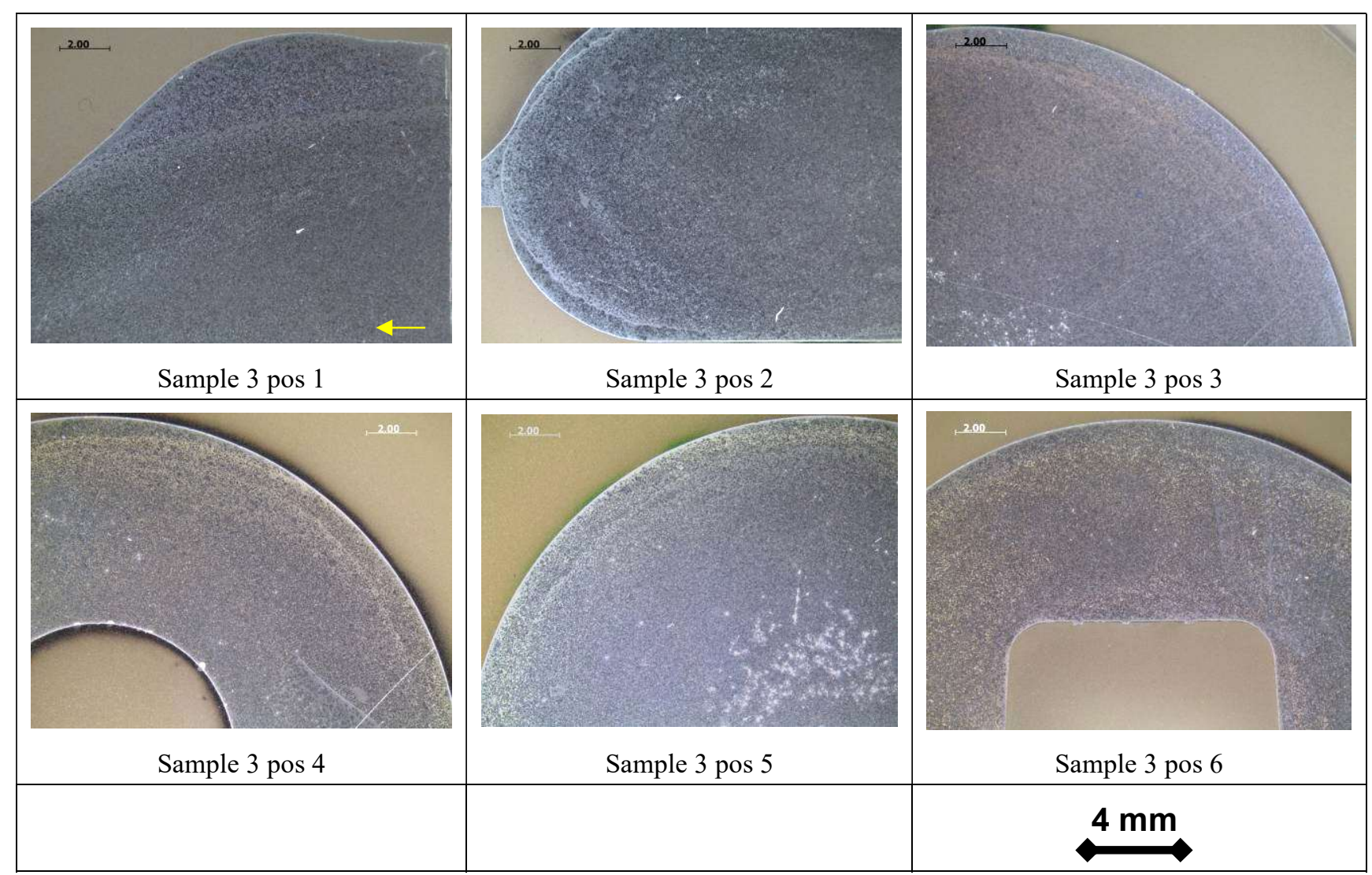

Fig.3 Typical etched optical pictures within trial 3 for piston velocity $0.15 \mathrm{~m} / \mathrm{s}$. Positions from where the sample is taken in the shaped component can be seen in figure 1 .

Figure 4 shows typical images from optical microscopy, LOM. Three positions are displayed: (1) outside the band, (2) band and (3) inside band. Area (1) is closest to the surface and experiences more rapid cooling than the inner regions; which can be seen in the mixture of globular grains and rosette shaped and/or dendritic grains; the latter having formed during the rapid "quenching" of the liquid in the slurry. The centre part, area (3) in fig 4, is densely packed with primary globules. In comparison with area (1) the globules are slightly coarser and significantly bigger than the few globules present in the band (2). The band (2) consists of a narrow shear band containing a high-volume fraction of eutectic.

Small globular particles should result in a narrower band due to the smaller distances between the particles, compared to coarse equiaxed crystals, which need more space to move around each other. Therefore, they give intergranular liquid more space and subsequently, more solute to segregate during shearing. Luo et al. [15] presents mechanical analyses of semi-solid metals, which indicate that under shear deformation SSM can appear as shear thinning if the grain boundary is inhomogeneously migrating, due to different expansion of transition liquid layers. If these transition liquid layers are broken, and a flood current is developed rather than to retain the adhesive liquid films, then the
SSM behave as shear thickening. If these narrow bands in SSM are formed under different mechanisms than bands in equiaxed dendritic alloys, as proposed by Gourlay et al. [10], it is possible that shear thickening liquid flooding is observed in SSM HPDC.

Generally, it is observed that the intermetallic phases are more common and smaller in the band region, see Figs. 5 and 7. Otarawanna et al. [10] has also observed this phenomenon in their study of HPDC material. They found that the intermetallic phases were coarser within the bands. In the current samples, small $\mathrm{Cu}$-bearing intermetallics are concentrated in the band, whereas $\mathrm{Fe}$ - and $\mathrm{Mn}$-bearing intermetallics are evenly distributed in the microstructure and equal in size as can be seen in the EDX-mapping images in Fig. 5. SEM images in fig. 6 and 7 show the band region in both SE and BSE detector. Lighter areas indicate intermetallic phases, grey areas are the eutectic Al-Si and black areas are the pro-eutectic $\mathrm{Al}$.

Areas (1) and (3) in fig. 4 show that the fraction solid of globules, fs, is quite different from the initial fs. The slurry is prepared to approximately $30 \%$ fs of globules; still area (1) generally has lower fs than the initial, whereas area (3) generally has higher fs of globules. 


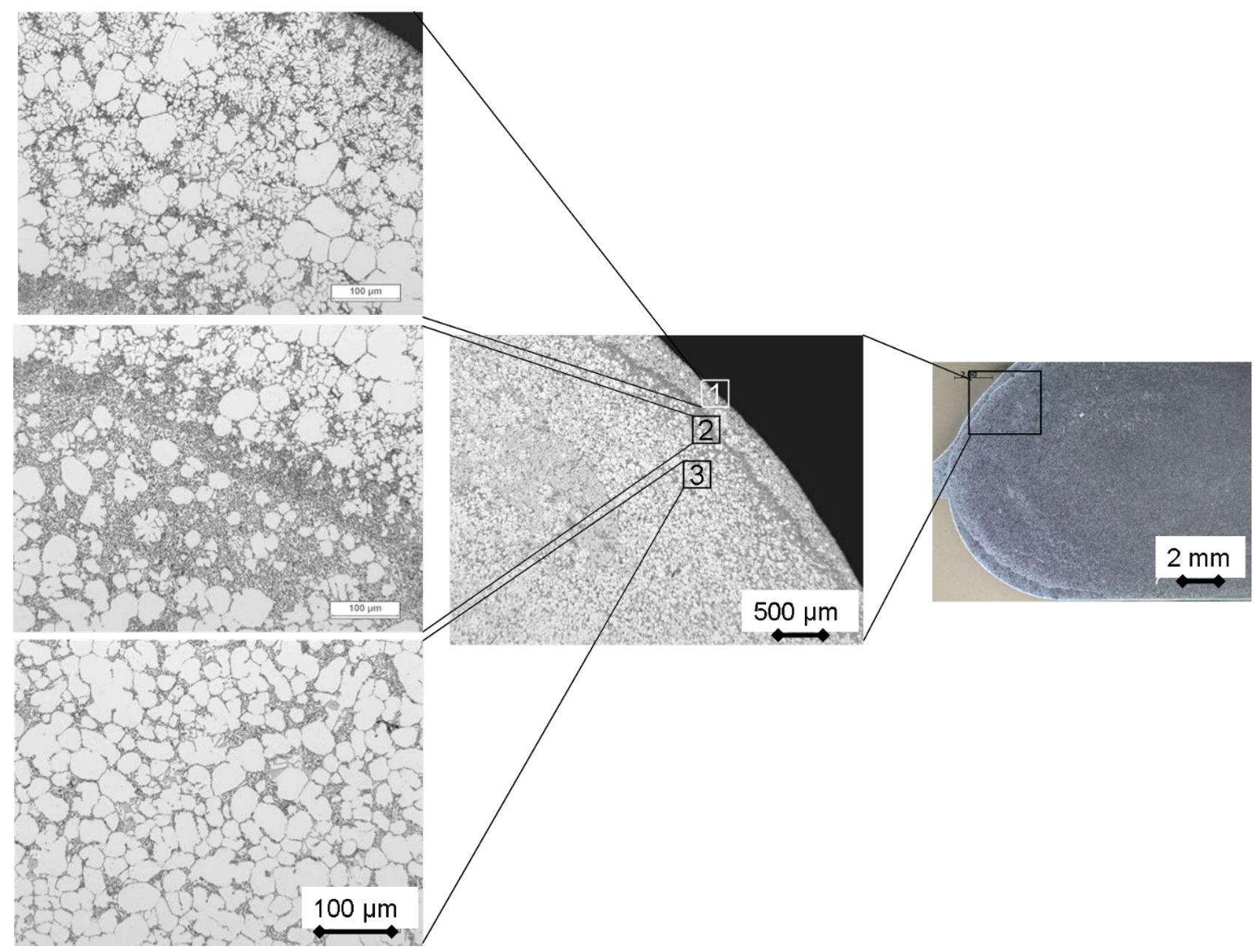

Fig.4 Etched pictures from trial 3 position 2, at piston velocity $0.15 \mathrm{~m} / \mathrm{s}$, showing the typical microstructure in area 1,2 and 3 .

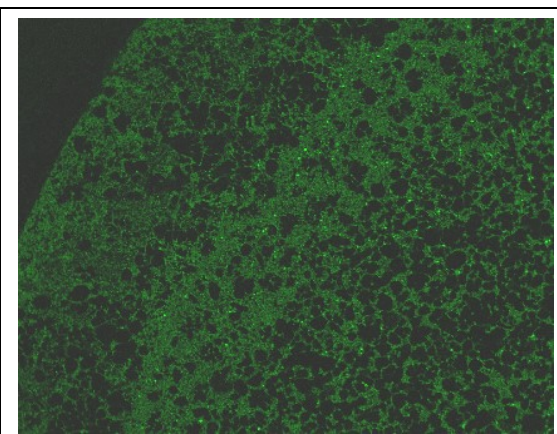

a

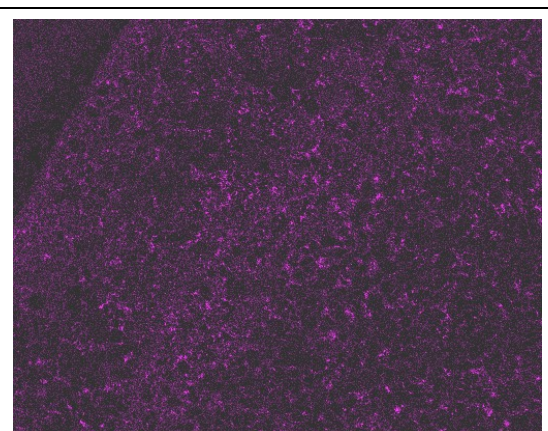

$\mathrm{b}$

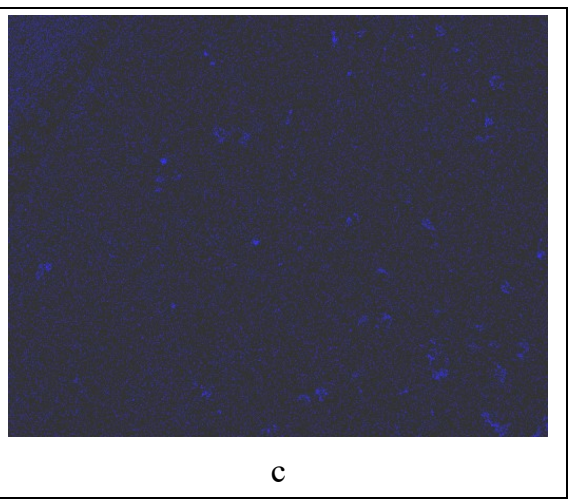

C

Fig.5 SEM image showing EDX-mapping with regards to a) Si distribution b) $\mathrm{Cu}$ distribution and c) Mn distribution, where more intense colour indicates an increase in concentration. Within the band there seems to be an increase in smaller Cu-rich phases, whereas the Mn-rich phases are evenly distributed.

According to previous research findings by Laukli et al. [4], during shearing in semi-solid castings the ESC migrate towards the centre of flow due to a combination of lift forces and wall effects. Laukli et al. also found that fs affected the distribution of ESC's. At lower fs the centre region was strongly compacted whereas for higher $\mathrm{fs}$, the region of migrating ESC was larger and closer to the surface but not as compacted. In this study with $30 \% \mathrm{fs}$, it is seen that smaller globules are more densely compacted in the centre compared to slightly larger globules in a sparsely compacted surface. 


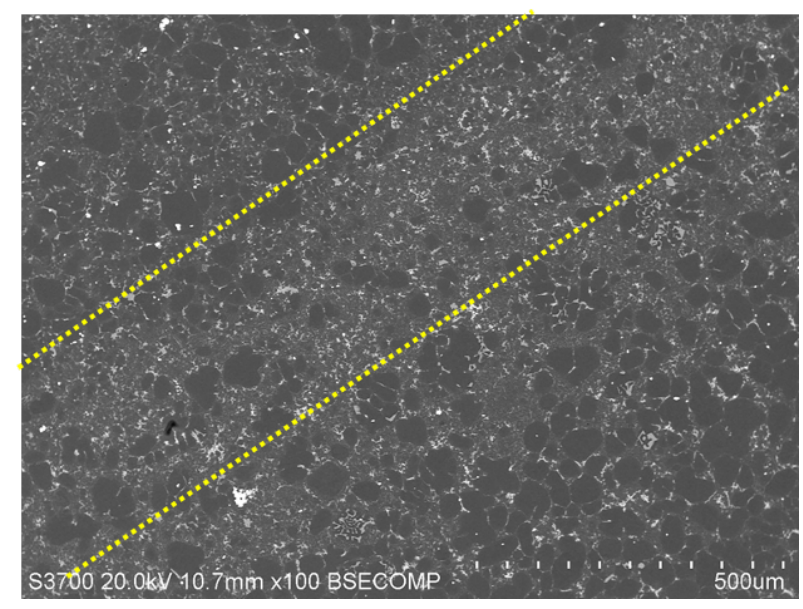

Fig.6 SEM BSE image covering a band, diagonally over image inside dotted lines. Dark areas are primary Al, grey areas are $\mathrm{Al}-\mathrm{Si}$ eutectic and white dots are $\mathrm{Cu}$-rich intermetallic phases.

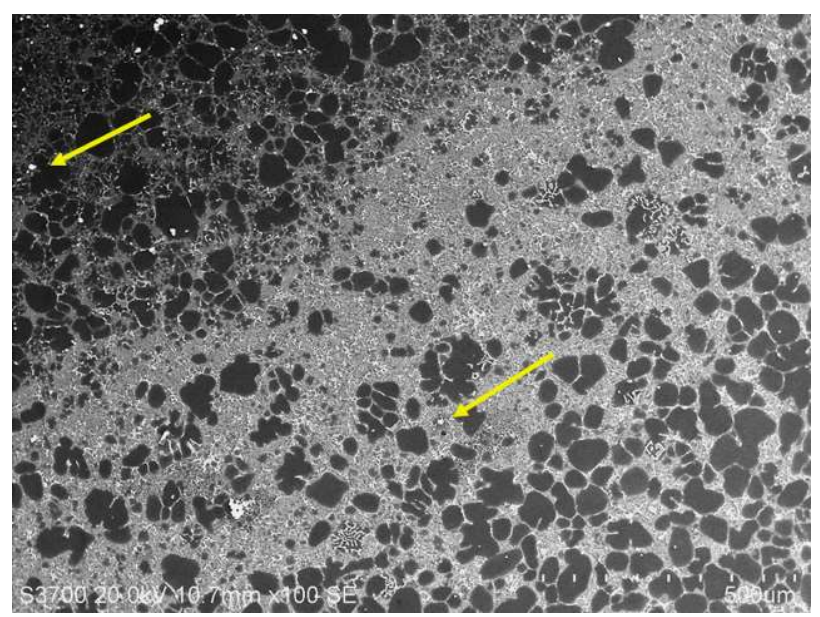

Fig.7 SEM SE image displaying the band, light area cross the diagonal. The arrows are pointing out the intermetallic phases, which are bigger outside the band compared to within the band area. Dark areas are primary $\mathrm{Al}$, grey areas are Al-Si eutectic and white dots are $\mathrm{Cu}$-rich intermetallic phases. The same scale bar is used in both Fig. 6 and 7.

\section{Conclusions}

The following concluding remarks can be made based on the observations in this study:

1) At lower phase 1 filling velocities, multiple defect bands were observed in the components

2) No porosity was found in the defect band, which only contained positive macrosegregation of eutectic

3) No difference in band position was obvious

4) Intermetallic phases are evenly distributed, but smaller in band

\section{Acknowledgements}

The author (MB) acknowledges the Swedish Agency for Innovation System (VINNOVA) and
Swerea SWECAST (the Swedish foundry association) for financial support.

\section{References}

[1] C. M GOURLAY, H. I. LAuKLI, A. K. DAHLE: Defect band Characteristics in Mg-Al and Al-Si High-Pressure Die Castings, Metallurgical and Materials Transactions A, 2007, 38A: 1833-1844

[2] C. M. GOURLAY, A. K. DAHLE: Dilitant shear bands in solidifying metals, Nature, 2007, 445: 70-73

[3] C. M. GOURLAY, H. I. LAUKLI, A. E. DAHLE: Segregation Band Formation in A1-Si Die Castings, Metallurgical and Materials Transactions A, 2004, 35A: 2881-2891

[4] H. I LAUKLI, C. M. GOURLAY, A. K. DAHLE: Migration of crystals during the Filling of Semi-Solid Castings, Metallurgical and Materials Transactions A, 2005, 36A: 805-818

[5] H. I LAUKLI, C. M. GOURLAY, A. K. DAHLE, OTTO LOHNE: Effects of Si content on defect band formation in hypoeutectic Al-Si die castings, Materials Science and Engineering A, 2005, 413-414: 92-97

[6] C. M. GOURLAY, S. OtARAWANNA, H. I. LAUKLI, A. K. DAHLE: An Overview of Defect Bands in High Pressure Die Castings, Die Castings Engineer, 2008, Jan: 32-35

[7] C. M. GOURLAY, B MEYLAN, A. K. DAHLE: Shear mechanisms at $0-50 \%$ solid during equiaxed dendritic solidification of an AZ91 magnesium alloy, Acta Materialia, 2008, 56: 3403-3413.

[8] S. OtARAWANNA, C. M. GOURLAY, H. I. LAUKLI, A. K. DAHLE: The Influence of Intensification Pressure on the Gate Microstructure of AlSi3MgMn High Pressure Die Castings, Materials science Forum, 2009, 618-619: 607-610

[9] S. OTARAWANNA, C. M. GOURLAY, H. I. LAUKLI, A. K. DAHLE: Microstructure Formation in AlSi4MgMn and AlMg5Si2Mn High-Pressure Die Castings, Metallurgical and Materials Transactions A, 2009, 40A: 1645-1659

[10] S. OtARAWANNA, C. M. GOURLAY, H. I. LAUKLI, A. K. DAHLE: The thickness of defect bands in high-pressure. Die castings, Materials Characterization, 2009, 60(12): 1432-1441.

[11] C. M. GOURLAY, S. OTARAWANNA, B. MEYLAND, A. K. DAHLE: Reynolds' Dilatancy and Shear Bands in Semi-solid Alloys, Solid State Phenomena, 2008, 141-143: 337-342.

[12] S. OTARAWANNA, C. M. GOURLAY, H. I. LAUKLI, A. K. DAHLE: Agglomeration and Bending of equiaxed crystals during solidification of hypoeutectic $\mathrm{Al}$ and $\mathrm{Mg}$ alloys. Acta Materialia, 2009, 58(1): 261-271.

[13] H. CAO, M. WESSÉN: Characteristics of microstructure and banded defects in die cast AM50 magnesium components. International Journal of Cast Metals Research, 2005, 18(6): 377-384.

[14] H CAO, M. WESSÉN, O. GRANATH: Effect of injection velocity on porosity formation in a rheocast $\mathrm{Al}$ component using RHEOMETAL $^{\mathrm{TM}}$ process. International Journal of Cast Metals Research, 2010, 23(3):158-163.

[15] S. LUO, Q. CHEN, X. GAO: Mechanical Analysis of Semi-Solid Metals Shear Deformation during Compression, Solid State Phenomena, 2008, 141-143: 439-44 
